\title{
Platelet microRNA-15b protects against high platelet reactivity in patients undergoing percutaneous coronary intervention through Bcl-2-mediated platelet apoptosis
}

\author{
Jinghan Wang, Yi Yao, Jiahui Zhang, Xiaofang Tang, Xianmin Meng, Miao Wang, Lei Song, Jinqing Yuan \\ State Key Laboratory of Cardiovascular Disease, Fuwai Hospital, National Center for Cardiovascular Diseases, Chinese Academy of Medical \\ Sciences and Peking Union Medical College, Beijing 100037, China \\ Contributions: (I) Conception and design: J Wang; (II) Administrative support: J Yuan, X Meng; (III) Provision of study materials or patients: J Wang, \\ Y Yao; (IV) Collection and assembly of data: J Wang, J Zhang; (V) Data analysis and interpretation: All authors; (VI) Manuscript writing: All authors; \\ (VII) Final approval of manuscript: All authors. \\ Correspondence to: Jinqing Yuan. Department of Cardiology, Fuwai Hospital, National Center for Cardiovascular Diseases, Chinese Academy of \\ Medical Sciences and Peking Union Medical College, Beijing 100037, China. Email: jqyuan132@sina.com.
}

Background: High platelet reactivity (HPR) and low platelet reactivity (LPR) are associated with an increased risk of ischemic/bleeding events in patients undergoing percutaneous coronary intervention (PCI). The role platelet miRNAs carry out in platelet reactivity regulation is largely unknown.

Methods: In this study, we profiled the expression pattern of platelet miRNA in patients undergoing PCI with HPR ( $=4)$ and LPR $(n=4)$ by miRNA microarray screening. The candidate miRNAs were further validated in a larger sample of $17 \mathrm{LPR}$ and $22 \mathrm{HPR}$ patients by quantitative reverse-transcription polymerase chain reaction (RT-qPCR), and miR-15b was found differentially expressed. MiR-15b mimic and inhibitor were transfected into MEG-01 cells, then Bcl-2 protein expression and cell apoptosis were assessed. The relationship between platelet reactivity and platelet apoptosis was further evaluated. ABT-737, a Bcl-2 inhibitor was used to induce platelet apoptosis in PCI patients in vitro, and the influence of enhanced platelet apoptosis on platelet reactivity was explored.

Results: Two miRNAs were found to be differentially expressed in patients with LPR and HPR using microarray system. Furthermore, the expression of miR-15b, a miRNA known to induce cell apoptosis via targeting of $\mathrm{Bcl}-2$, was confirmed by RT-qPCR $(\mathrm{P}=0.020)$ to be $1.4 \times$ higher in the platelets of LPR patients than in those of HPR patients. Overexpression of miR-15b was demonstrated to suppress Bcl-2 protein expression and enhance cell apoptosis in a megakaryocyte cell line (MEG-01). The platelets of LPR patients expressed lower levels of Bcl-2 protein than those of HPR patients, and an inverse relationship between platelet reactivity and platelet apoptosis was observed among 44 patients who underwent PCI. Inducing platelet apoptosis in PCI patients in vitro, we observed that their platelet reactivity was decreased in a dosedependent manner.

Conclusions: Through the promotion of platelet apoptosis, platelet miR-15b negatively regulates platelet reactivity in patients undergoing PCI. Platelet apoptosis may represent a novel antiplatelet target for overcoming HPR in PCI treatment.

Keywords: Platelet microRNA; platelet reactivity; platelet apoptosis; percutaneous coronary intervention (PCI)

Submitted Dec 15, 2019. Accepted for publication Jan 23, 2020.

doi: $10.21037 /$ atm.2020.02.88

View this article at: http://dx.doi.org/10.21037/atm.2020.02.88 


\section{Introduction}

Platelet P2Y12 receptor antagonists play a central role in antiplatelet therapy among patients with acute coronary syndromes (ACS) and those undergoing percutaneous coronary intervention (PCI) (1-3). However, on-clopidogrel platelet reactivity varies widely among patients, with the risk of ischemic/bleeding events heightened by high or low platelet reactivity (HPR/LPR) (4-10). Prasugrel and ticagrelor, new $\mathrm{P} 2 \mathrm{Y} 12$ receptor antagonists, have been introduced to counter HPR, yet a small amount of interindividual variability is still observed $(11,12)$. Moreover, major concerns have been raised by their habit of increasing the occurrence of bleeding complications (13-15), indicating that interindividual variation in platelet reactivity still exists in clinical practice.

Given that HPR is proved to be an independent predictor of thrombotic events including death, myocardial infarction and stent thrombosis in patients undergoing PCI (6-9), many studies have explored the mechanisms underlying the variability in platelet responsiveness. In addition to clinical factors such as age, female gender, diabetes mellitus, and body mass index (16-20), genetic factors have been a central focus in numerous investigations. Notably, cytochrome P450 (CYP) 2C19*2 loss-of-function carrier is associated with HPR and increased occurrence of thrombotic complications (20-23). However, CYP2C19 single-nucleotide polymorphisms (SNPs) alone account for only $5-12 \%$ of the interindividual variability in platelet reactivity $(20,21)$; other genetic factors are yet to be clarified.

MicroRNAs (miRNAs) are short non-coding RNAs that modulate gene expression by binding target mRNAs to induce degradation or repress translation, thus playing a critical role in the regulation of various cellular processes, including proliferation, apoptosis, and differentiation $(24,25)$. Although anucleated, platelets contain an abundant and diverse set of miRNAs (26-28). Platelet-derived miRNAs (miR-223 and miR-191) in plasma were found to decrease with use of antiplatelet drugs (29). Notably, miR-223, which is one of the highest expressed miRNAs in platelets, was proved to target P2Y12 mRNA (26), and platelet and plasma miR-223 was further demonstrated to correlate with HPR in patients with coronary heart disease (CHD) $(30,31)$. Additionally, the miRNA and mRNA expression profiles of epinephrine-induced hyper- and hypo-reactive platelets in healthy individuals were compared through microarray systems, and 4 miRNAs-miR-96, miR-200b, miR-495 and miR-107 were found to be associated with platelet reactivity
$(27,32)$. The findings mentioned above suggest that in healthy individuals and CHD patients platelet reactivity may be regulated by platelet miRNAs. In fact, the risk of HPRor LPR-related ischemic or bleeding occurrences is highest in patients who have undergone PCI (4-10). Therefore, performing miRNA expression profiling in platelets of PCI patients, discovering differentially expressed platelet miRNAs between patients with LPR and HPR, and mechanistically elucidating how miRNAs may regulate platelet function are all essential tasks.

In this study, we explored the expression pattern of platelet miRNAs in patients who underwent PCI and identified an apoptosis-related miRNA, miR-15b, which is differentially expressed in the platelets of LPR and HPR patients. Although apoptosis occurs in anucleate platelets (33-35), there is gap in our understanding of the relationship between platelet apoptosis and platelet reactivity. Thus, this study also determined the relationship between platelet miR-15b, platelet apoptosis and interindividual variability of platelet reactivity in patients treated by PCI.

\section{Methods}

\section{Materials}

Human CD45 microbeads were obtained from Miltenyi Biotec (Bergisch Gladbach, Germany). Prostaglandin $\mathrm{E}_{1}$ $\left(\mathrm{PGE}_{1}\right)$, and JC-1 were purchased from Sigma-Aldrich (St. Louis, MO, USA). FITC Annexin V Apoptosis Detection Kit and PE Mouse Anti-Human CD61 were obtained from BD Biosciences (Heidelberg, Germany). VerifyNow P2Y12 assay was purchased from Accumetrics (San Diego, CA, USA), and adenosine diphosphate (ADP) was from Helena Laboratories (Beaumont, TX, USA). Anti-Bcl-2, antiCaspase-3, and anti- $\beta$-actin rabbit antibody were sourced from Cell Signaling Technology (Danvers, MA, USA). ABT-737 was from Selleck Chemical (Houston, TX, USA). mirVana miRNA Isolation Kit, Taqman microRNA primers (hsa-miR-145-5p and hsa-miR-15b-5p), Taqman microRNA Reverse Transcription Kit, Taqman Universal Master Mix II, mirVana miRNA mimic and inhibitor (hsa-miR-15b-5p), mirVana miRNA mimic and inhibitor negative control \#1, and Lipofectamine RNAiMAX reagents were purchased from Applied Biosystems (Foster City, CA, USA).

\section{Study population}

Consecutive patients were enrolled in the cohort if they 
had undergone PCI with drug-eluting stents and were being treated with dual antiplatelet therapy of aspirin and clopidogrel. According to the clinical practice of the institution, patients received a loading dose $(300 \mathrm{mg})$ of clopidogrel prior to PCI and, after that, a maintenance dose (75 mg) daily. VerifyNow P2Y12 assay was used to evaluate platelet reactivity on the morning of day 1 (12-24 hours) and day 2 (36-48 hours) after PCI. To rule out an elevation in transient platelet reactivity in patients during the treatment, only those who presented consistent LPR or HPR on both day 1 and day 2 were recruited into the HPR group or the LPR group. We recruited another cohort of 44 patients who were undergoing PCI with drug-eluting stents and assessed the platelet function and levels of platelet apoptosis 12-24 hours following PCI. This facilitated evaluation of the relationship between platelet reactivity and platelet apoptosis. For both cohorts, the exclusion criteria were defined as established platelet function disorders or whole blood platelet counts of less than $100 \times 10^{3} / \mu \mathrm{L}$. The study protocol was approved by the Medical Ethics Committee of Fuwai Hospital of Peking Union Medical College and the Chinese Academy of Medical Sciences. Written informed consent was obtained from each patient.

\section{Platelet function testing}

To measure platelet reactivity, the VerifyNow P2Y12 assay was performed in accordance with the manufacturer's instructions. The VerifyNow P2Y12 assay is a point-ofcare turbidimetry-based optical detection that estimates the inhibition of $\mathrm{P} 2 \mathrm{Y} 12$ receptors by their antagonists by assessing the level of $\mathrm{P} 2 \mathrm{Y} 12$ receptor activation. ADP simultaneously activates $\mathrm{P} 2 \mathrm{Y} 1$ and $\mathrm{P} 2 \mathrm{Y} 12$ receptors, thus the disposable assay device contains $20 \mu \mathrm{M}$ ADP to induce platelet aggregation and $22 \mathrm{nM}$ PGE1 to reduce P2Y1 activation by ADP. The assay reports values in P2Y12 reaction units (PRU) with a proprietary algorithm. In this study, HPR was defined as $\geq 300$ PRU and LPR as $<170$ PRU in order to maximally discriminate between the patients in the 2 groups.

Since the VerifyNow P2Y12 assay was a whole blood assay which was unable to evaluate platelet reactivity in platelet-rich plasma, after treatment of ABT-737, platelet reactivity was assessed using light transmittance aggregometry (LTA) assay. To induce platelet aggregation, platelet-rich plasma was stimulated with $20 \mu \mathrm{M}$ ADP and $22 \mathrm{~nm}$ PGE1 in accordance with the reagents within
VerifyNow P2Y12 assay devices. Platelet aggregation was measured by a 4-channel LBY-NJ4 light transmittance aggregometer (Precil, Beijing, China) and expressed as the maximum percent change in light transmittance from platelet-poor plasma which was set as a reference.

\section{Platelet Isolation and total platelet RNA extraction}

On day 2, as previously described, leukocyte-depleted platelets (LDPs) were prepared after PCI, which yielded a purity of less than one leukocyte per five million platelets (27). Briefly, fasting venous blood was drawn into acid citrate dextrose (ACD) tubes (BD Vacutainer) through a 21-gauge needle and centrifuged at $180 \mathrm{~g}$ for 20 minutes to obtain platelet suspension. Ethylenediaminetetraacetic acid was added at a final concentration of $2 \mathrm{~mm}$. Another centrifugation at $180 \mathrm{~g}$ was then performed for 15 minutes to minimize contamination of leukocytes and erythrocytes. Platelets were pelleted at 1,000 g for 15 minutes and then resuspended in $1 \mathrm{~mL}$ Beads buffer, which was prepared by diluting MACS BSA stock solution 1:20 with autoMACS rinsing solution. For platelet purification, $40 \mu \mathrm{L}$ human CD45 MicroBeads reagent was added to the platelet suspension and incubated for 45 minutes with gentle mixing. LDPs were collected by depleting CD45-positive cells using magnetic separating unit. LDPs were lysed in lysis/binding buffer, and total platelet RNA was harvested with the mirVana miRNA Isolation Kit, according to the manufacturer's instructions. Total RNA was eluted in $80 \mu \mathrm{L}$ elution solution and stored at $-80{ }^{\circ} \mathrm{C}$ until further processing.

\section{MicroRNA microarray and data analysis}

To determine the diverse miRNA expression in platelets between LPR and HPR patients, we performed miRNA expression profiles of LDP samples from four LPR and four HPR patients using Agilent human miRNA microarray (version 19.0) system (Agilent technologies, Santa Clara, CA, USA). The miRNA molecular labeling, array hybridization and data scanning were performed at Biochip Company (Shanghai, China), according to the protocols of the Agilent miRNA microarray system. Raw data were normalized by Quantile algorithm, Gene Spring Software 11.0. miRNA microarray data has been deposited in the National Center for Biotechnology Information Gene Expression Omnibus (http://www.ncbi.nlm.nih.gov/geo/), with the accession number GSE59488. 


\section{Quantitative reverse-transcription polymerase chain reaction ( $R T-q P C R)$}

A larger LDP sample of 17 LPR and 22 HPR patients by RT-qPCR was used to further validate the candidate miRNAs analyzed from microRNA microarray. Total RNA was reversely transcribed into cDNA with specific Taqman microRNA primers (hsa-miR-145-5p and hsa-miR-15b-5p) and the Taqman MicroRNA Reverse Transcription Kit. After mixing cDNA with Taqman Universal Master Mix II and miRNA-specific Taqman Small RNA Assay (20x), reactions were carried out on the 7300 real-time PCR system (Applied Biosystems, Foster City, CA, USA). miRNA expression was calculated by correlating the mean values of miRNAs with U6 using the $2^{-\Delta \Delta C T}$ method.

\section{miRNA transfection}

Platelets are formed and released from their precursor cells-megakaryocytes. As miRNA expression profiling in megakaryocyte cell line-MEG-01 (ATCC, CRL-2021) correlates with that in human platelets, Nagalla et al. used MEG-01 cells for platelet miRNA transfection (27). MEG-01 cells were cultured in Roswell Park Memorial Institute (RPMI) 1640 medium containing 10\% (v/v) fetal bovine serum (FBS) and were transfected with mirVana miRNA mimics or inhibitor (hsa-miR-15b-5p, $150 \mathrm{~nm}$ ) by Lipotfectamine RNAiMAX reagents. The negative controls in the experiment were in the form of mirVana miRNA mimic negative control \#1 and inhibitor negative control \#1. miRNA mimics are double-stranded RNAs which mimic endogenous precursor miRNAs, while miRNA inhibitors are designed to specifically bind to and inhibit the activity of endogenous miRNAs. Twelve hours later, the cells were harvested for either western blot analysis or measurement of apoptosis.

\section{Western blot analysis}

LDPs or MEG-01 cells were lysed in RIPA buffer with protease inhibitor cocktail (Roche Diagnostics, Mannheim, Germany). Lysates were subjected to $12 \%$ sodium dodecyl sulfate-polyacrylamide gel electrophoresis (SDS-PAGE), electrotransferred to polyvinylidene difluoride (PVDF) membranes (Millipore, Darmstadt, Germany), incubated with specific antibodies, and detected with ECL-enhanced chemi-luminescence system (Bio-Rad, Hercules, CA, USA). ImageJ was used to perform protein quantification.

\section{Flow cytometric measurement of apoptotic events}

ABT-737-treated platelets were stained with anti-CD61$\mathrm{PE}$ and Annexin V-FITC to detect phosphatidylserine (PS) exposure in platelet (CD61)-positive events. MEG-01 cells were stained with Annexin V-FITC and propidium iodide (PI). Mitochondrial membrane potential $(\triangle \Psi \mathrm{m})$ depolarization was determined with JC-1 $(5 \mu \mathrm{g} / \mathrm{mL})$. The final volume was $500 \mu \mathrm{L}$ for an immediate analysis by FACSCalibur flow cytometry (BD Biosciences, CA, USA).

\section{Platelet treatment}

Blood-citrate tubes were centrifuged at $180 \mathrm{~g}$ for 10 minutes and again at 1,000 $\mathrm{g}$ for 10 minutes to obtain platelet-rich plasma and platelet-poor plasma, respectively. For ABT737-induced platelet apoptosis, platelet-rich plasma was incubated with various concentrations of ABT-737 (2.5, 5, $10 \mu \mathrm{M})$ for 2 hours at $37^{\circ} \mathrm{C}$. DMSO was used as a vehicle control of ABT-737.

\section{Statistical analysis}

A $t$-test was carried out to compare continuous variables, and the Chi-square test was applied to compare the distribution of categorical variables. The association between platelet miR-15b expression and platelet reactivity was determined by binary logistic regression analysis. Pearson's correlation coefficient, linear regression, binary logistic regression and receiver operator characteristic (ROC) curve analysis were used to determine the correlation between platelet reactivity and platelet apoptosis. All statistics were performed with SPSS 20.0 (SPSS, Inc., Chicago, IL, USA). A value was considered statistically significant when $\mathrm{P}<0.05$.

\section{Results}

\section{Patient characteristics}

We enrolled a cohort of 290 patients who underwent PCI. According to the platelet function testing, 21 of these patients were defined as LPR and 26 as HPR. Among these patients, four with LPR and four HPR were included in miRNA microarray detection. The baseline characteristics of these eight patients are displayed in Table S1. To further validate the candidate differentially expressed miRNAs, RT-qPCR was conducted in LDPs of other 17 patients with LPR and 22 HPR. Their characteristics are summarized in Table 1. 
Table 1 Characteristics of patients with LPR and HPR in the validation group

\begin{tabular}{lccc}
\hline Variables & $\begin{array}{c}\text { LPR group } \\
(n=17)\end{array}$ & $\begin{array}{c}\text { HPR group } \\
(n=22)\end{array}$ & $P$ \\
\hline
\end{tabular}

$\begin{array}{lccc}\text { Clinical parameters } & & & \\ \text { Age (years) } & 51.94 \pm 10.37 & 63.91 \pm 8.20 & <0.001 \\ \text { Male sex (\%) } & 94.1 & 63.6 & 0.052 \\ \text { BMl (kg/m²) } & 26.15 \pm 2.73 & 25.53 \pm 2.60 & 0.477 \\ \text { Hypertension (\%) } & 58.8 & 72.7 & 0.497 \\ \text { Hyperlipidemia (\%) } & 76.5 & 81.8 & 0.709 \\ \text { Diabetes (\%) } & 29.4 & 36.4 & 0.740 \\ \text { Family CAD } & 17.6 & 27.3 & 0.704 \\ \text { history (\%) } & & & \\ \text { Current smoking (\%) } & 41.2 & 31.8 & 0.738 \\ \text { LVEF } & 56.62 \pm 9.69 & 58.86 \pm 8.68 & 0.459\end{array}$

Medications

\begin{tabular}{|c|c|c|c|}
\hline PPI (\%) & 17.6 & 31.8 & 0.464 \\
\hline Nitrates (\%) & 100 & 100 & 1.000 \\
\hline$\beta$-blockers (\%) & 94.1 & 86.4 & 0.618 \\
\hline ACEI (\%) & 29.4 & 22.7 & 0.721 \\
\hline ARB (\%) & 23.5 & 36.4 & 0.494 \\
\hline CCB (\%) & 41.2 & 68.2 & 0.115 \\
\hline Statins (\%) & 100 & 95.5 & 1.000 \\
\hline \multicolumn{4}{|l|}{ Laboratory parameters } \\
\hline WBC counts $\left(10^{9} / \mathrm{L}\right)$ & $7.49 \pm 1.56$ & $6.95 \pm 1.48$ & 0.284 \\
\hline Hemoglobin (g/L) & $147.12 \pm 15.28$ & $132.77 \pm 10.10$ & 0.000 \\
\hline Creatinine $(\mu \mathrm{mol} / \mathrm{L})$ & $80.89 \pm 14.67$ & $78.14 \pm 17.59$ & 0.606 \\
\hline \multicolumn{4}{|l|}{$\mathrm{PCl}$ parameters } \\
\hline $\begin{array}{l}\text { No. of stents } \\
\text { implanted }\end{array}$ & $1.76 \pm 1.15$ & $2.05 \pm 0.95$ & 0.409 \\
\hline $\begin{array}{l}\text { Left anterior } \\
\text { descending artery }\end{array}$ & 58.8 & 50.0 & 0.748 \\
\hline \multicolumn{4}{|c|}{ Platelet function parameters } \\
\hline $\begin{array}{l}\text { VerifyNow P2Y12 } \\
\text { (PRU), 1st day }\end{array}$ & $127.29 \pm 42.24$ & $351.00 \pm 30.05$ & $<0.001$ \\
\hline $\begin{array}{l}\text { VerifyNow P2Y12 } \\
\text { (PRU), 2nd day }\end{array}$ & $122.65 \pm 32.23$ & $338.91 \pm 34.26$ & $<0.001$ \\
\hline
\end{tabular}

Continuous variables are presented as mean \pm SD and categorical variables as percentage of the subjects. BMI, body mass index; CAD, coronary artery disease; LVEF, left ventricular ejection fraction; PPI, proton pump inhibitor; ACEl, angiotensin-converting enzyme inhibitor; ARB, angiotensin receptor blocker; CCB, calcium channel blocker; WBC, white blood cell; PRU, platelet reactivity unit; LPR, low platelet reactivity; HPR, high platelet reactivity.
Table 2 Differentially expressed platelet miRNAs between LPR and HPR in microarray analysis

\begin{tabular}{lcc}
\hline miRNAs & $P$ & Fold change (LPR/HPR) \\
\hline hsa-miR-145-5p & 0.031 & 0.549 \\
hsa-miR-15b-5p & 0.042 & 1.368 \\
\hline LPR, low platelet reactivity; HPR, high platelet reactivity.
\end{tabular}

\section{Platelet miRNA expression profiling}

To detect differentially expressed miRNAs in platelets of diverse platelet reactivity, we profiled miRNA expression in LDPs of the four LPR and four HPR patients using Agilent human miRNA microarray (version 19.0) system. In all, out of more than 1800 miRNAs that were scanned, 420 were positively detected in the platelets of all eight patients and are listed in Supplemental Table 2. Among these miRNAs, we found miR-145 and miR-15b were differentially expressed between patients with LPR and HPR $(\mathrm{P}<0.05$, Table 2). To confirm the miRNAs that were to platelet function, we measured the expression of these two miRNAs via $\mathrm{RT}-\mathrm{qPCR}$.

\section{Platelet miR-15b negatively correlates with platelet reactivity}

The expression of the candidate miRNAs (miR-145 and miR-15b) in the LDPs of 17 LPR and 22 HPR patients was compared through RT-qPCR. There was a $1.4 \times$ increase in platelet miR-15b expression in patients with $\mathrm{LPR}$ compared with those with HPR $(\mathrm{P}=0.020$, Figure 1$)$. There was no significant difference observed between the levels of platelet miR-145 in the two groups $(\mathrm{P}=0.718$, Figure 1$)$. Stepwise binary logistic regression was used to evaluate an independent association between platelet miR-15b expression and platelet reactivity. Variables such as gender, age, concentration of hemoglobin, and platelet miR-15 expression were included in this model. After adjustment for risk factors, we found that the expression of miR-15b in platelets was independently associated with LPR [odds ratio (OR), 118.10 (95\% confidence interval, 3.40 to 4102.96 ), $\mathrm{P}=0.008$, Table 3].

\section{miR-15b enhances apoptosis via targeting Bcl-2 in megakaryocytes}

miRNA prediction software, including TargetScan, miRanda, and Pictar, was used to scan miR-15b target 
Page 6 of 15

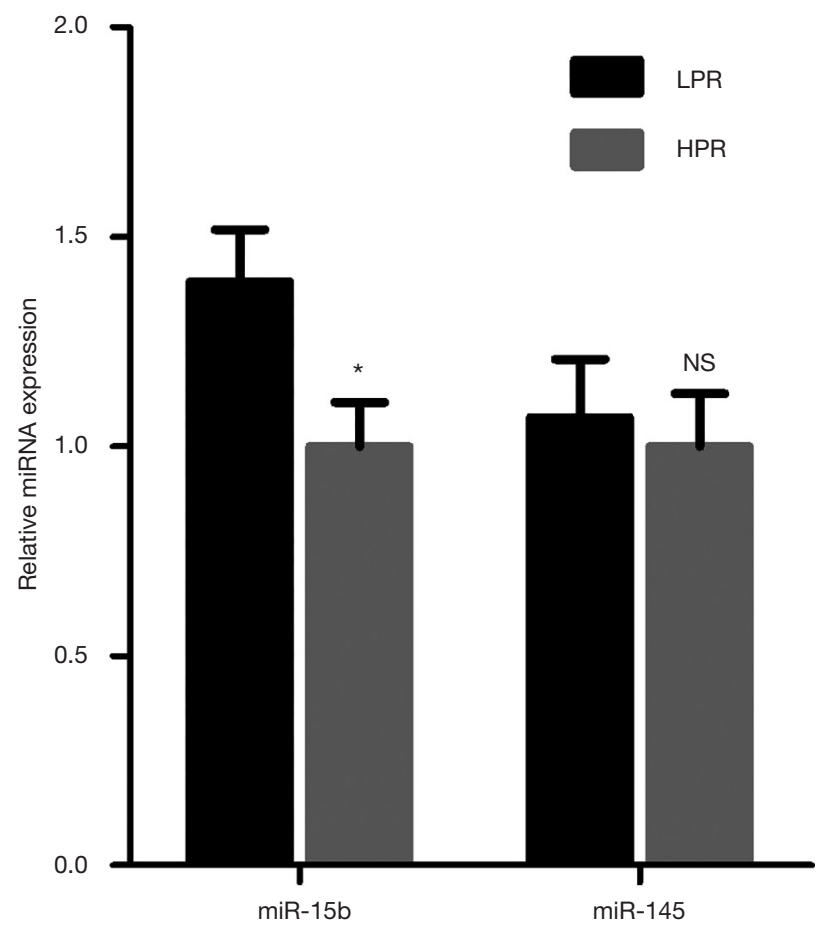

Figure 1 Increased expression of miR-15b in platelets of LPR patients. The levels of two miRNAs (miR-15b and miR-145) were detected in leukocyte-depleted platelets of 17 LPR and 22 HPR patients who underwent PCI by quantitative reverse-transcription polymerase chain reaction. The relative expression of the miRNAs was normalized to U6 expression using the $2^{-\triangle \Delta C T}$ method. Error bars represent SEM. NS indicates $\mathrm{P}>0.05$; *, $\mathrm{P}<0.05$. LPR, low platelet reaction; HPR, high platelet reactivity; PCI, percutaneous coronary intervention.

Table 3 Multivariate associations between potential risk factors and low platelet reactivity

\begin{tabular}{lcc}
\hline Variables & OR (95\% confidence interval) & $P$ \\
\hline $\begin{array}{l}\text { Platelet miR-15b } \\
\text { expression }\end{array}$ & $118.10(3.40-4102.96)$ & 0.008 \\
Age & $0.75(0.61-0.93)$ & 0.008 \\
Male sex & $30.90(1.16-825.67)$ & 0.041 \\
Hemoglobin & - & 0.218 \\
\hline
\end{tabular}

OR, odds ratio.

genes (36-38). Among the putative genes, Bcl-2 was also identified by several previous studies, and miR-15b was found to enhance cell apoptosis through its targeting of Bcl-2 (39-41). Therefore, we transfected miR-15b mimic
Wang et al. miR-15b regulates platelet reactivity through apoptosis
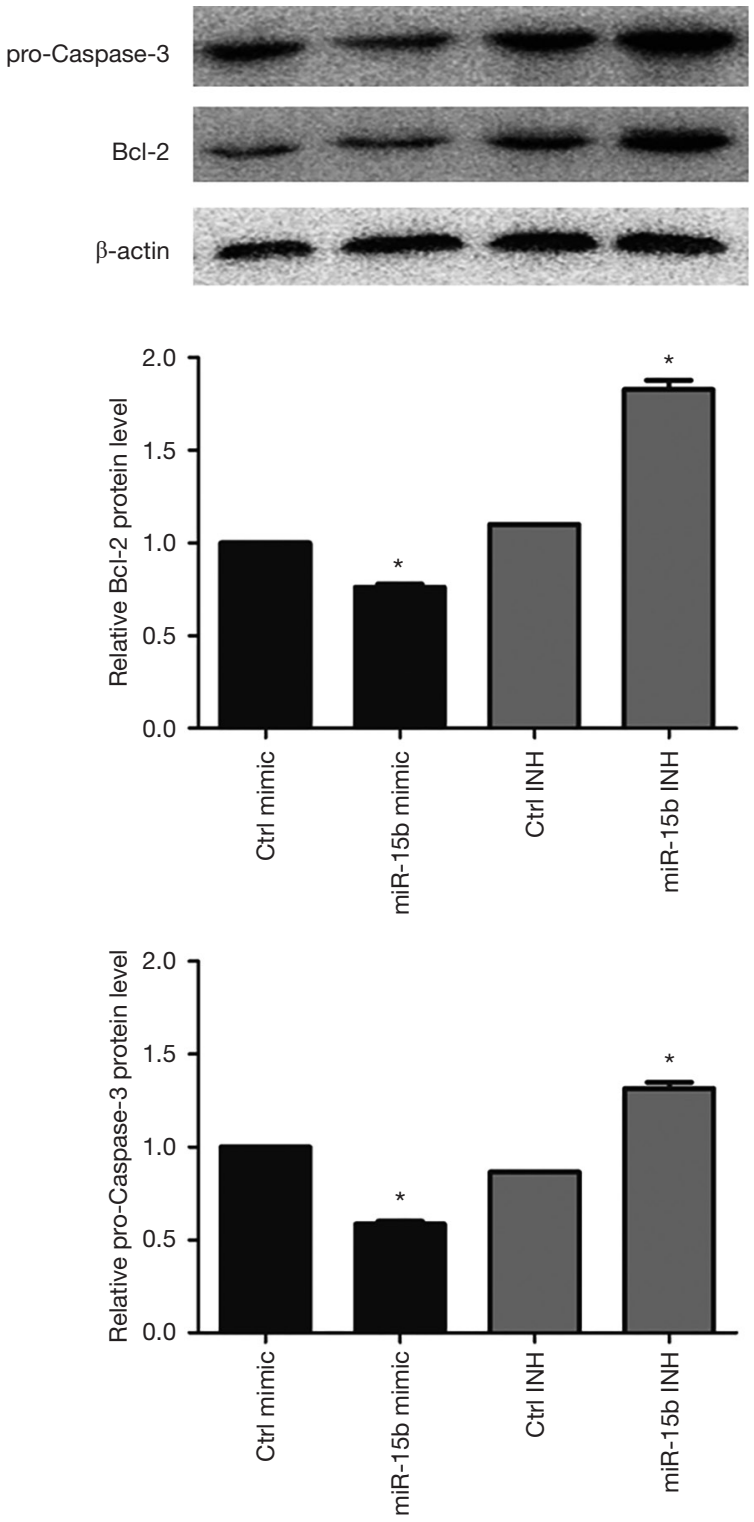

Figure 2 miR-15b suppresses the expression of Bcl-2 and proCaspase-3 proteins in MEG-01 cells. miR-15b mimic or inhibitor $(150 \mathrm{~nm})$ was transfected into MEG-01 cells, and miRNA mimic negative control \#1 or inhibitor negative control \#1 was used as a negative control. Cell protein lysates were harvested after 12 hours and then analyzed by western blot for Bcl-2 and pro-Caspase- 3 proteins. Protein levels were normalized to levels of b-actin. Data are mean $\pm \operatorname{SEM}(\mathrm{n}=3) .{ }^{*}, \mathrm{P}<0.05$.

and inhibitor into MEG-01 cells and then assessed protein expression and cell apoptosis. As shown in Figure 2, miR-15b mimic reduced 24\% Bcl-2 expression and miR-15b inhibitor elevated 1.8-fold in Bcl-2 expression in MEG-01 

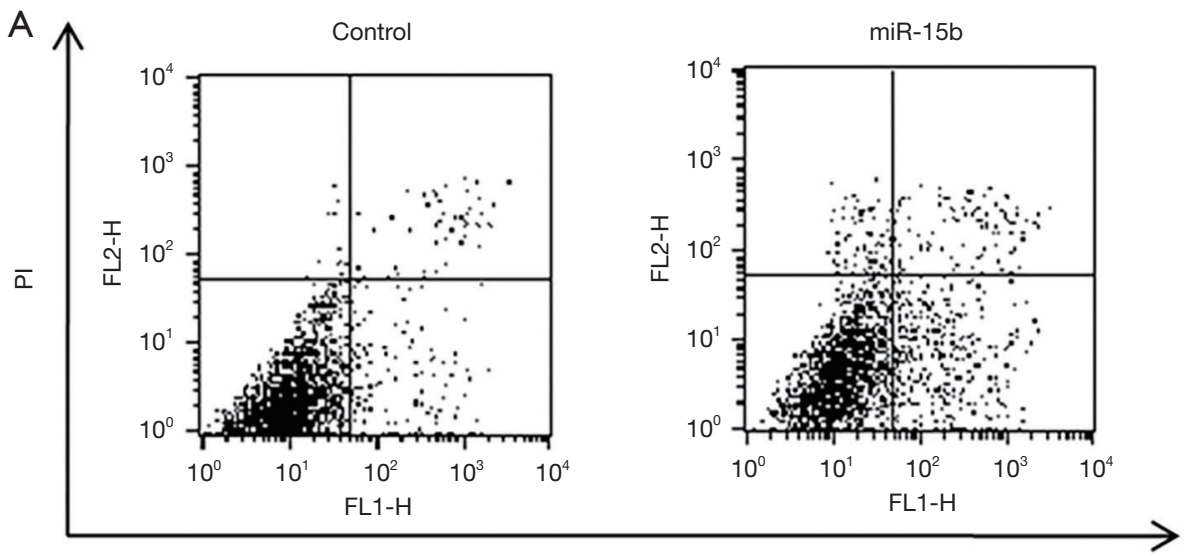

Annexin V

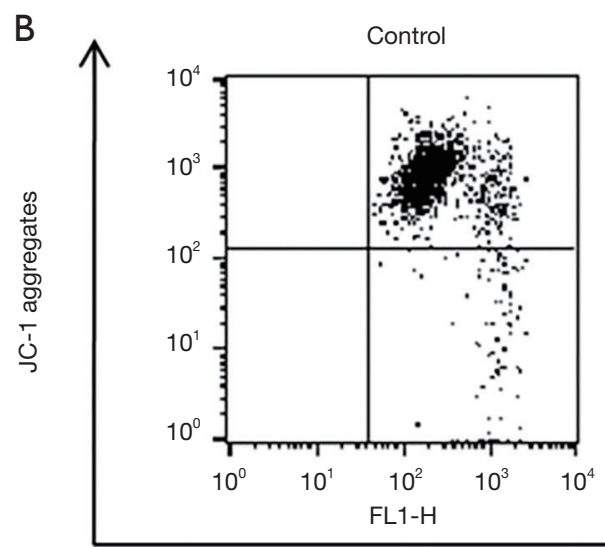

JC-1 monomers
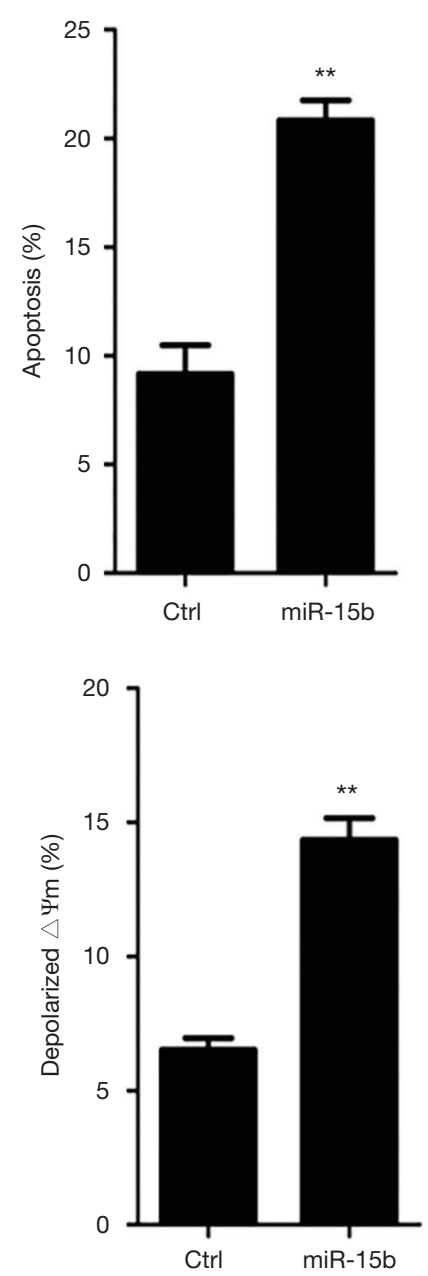

Figure 3 miR-15b induces apoptotic events in MEG-01 cells. miR-15b mimic or inhibitor (150 nm) was transfected into MEG-01 cells, and miRNA mimic negative control \#1 or inhibitor negative control \#1 was used as a negative control. Cells were harvested after 12 hours for evaluation of apoptotic events by flow cytometry. Data are mean \pm SEM $(n=3)$. (A) Cell apoptosis was assessed with Annexin V and propidium iodide staining. (B) Cell apoptosis was determined with mitochondrial membrane potential $(\triangle \Psi \mathrm{m})$ depolarization stained with $\mathrm{JC}-1(5 \mu \mathrm{g} / \mathrm{mL}) .{ }^{* *}, \mathrm{P}<0.01$.

cells $(\mathrm{P}=0.018 ; \mathrm{P}=0.019)$. The inhibition of antiapoptotic Bcl-2 triggers depolarization of $\triangle \Psi \mathrm{m}$, activation of caspases, and membrane externalization of PS, all of which are key markers for cell apoptosis (39-43). Caspase-3 is the main executioner of apoptosis, and its activation and subsequent apoptotic events are marked by decreased levels of procaspase-3 (44-46). We observed that miR-15b mimic induced a $42 \%$ knockdown of procaspase- 3 expression, and miR-15b inhibitor elevated procaspase- 3 expression 1.3 -fold $(\mathrm{P}=0.006 ; \mathrm{P}=0.021$, Figure 2). Moreover, we also found that miR-15b mimic induced a 2.3-fold increase in Annexin V and PI stained apoptotic events $(\mathrm{P}=0.002$, Figure $3 A)$, and a 2.2-fold increase in $\triangle \Psi \mathrm{m}$-depolarized cells $(\mathrm{P}=0.001$, Figure 3B).

\section{HPR patients express higher levels of Bcl-2 protein}

Given the proapoptotic role of miR-15b as a suppressor of Bcl-2 in MEG-01 cells, we next assessed the expression of Bcl-2 and procaspase-3 proteins in the platelets of patients with LPR $(\mathrm{n}=5)$ and HPR $(\mathrm{n}=5)$ using the western blot method. Patients with HPR showed 2.3- and 1.6-fold increases in the levels of platelet Bcl-2 and procaspase- 3 proteins, respectively, than those with LPR $(\mathrm{P}=0.003$, 

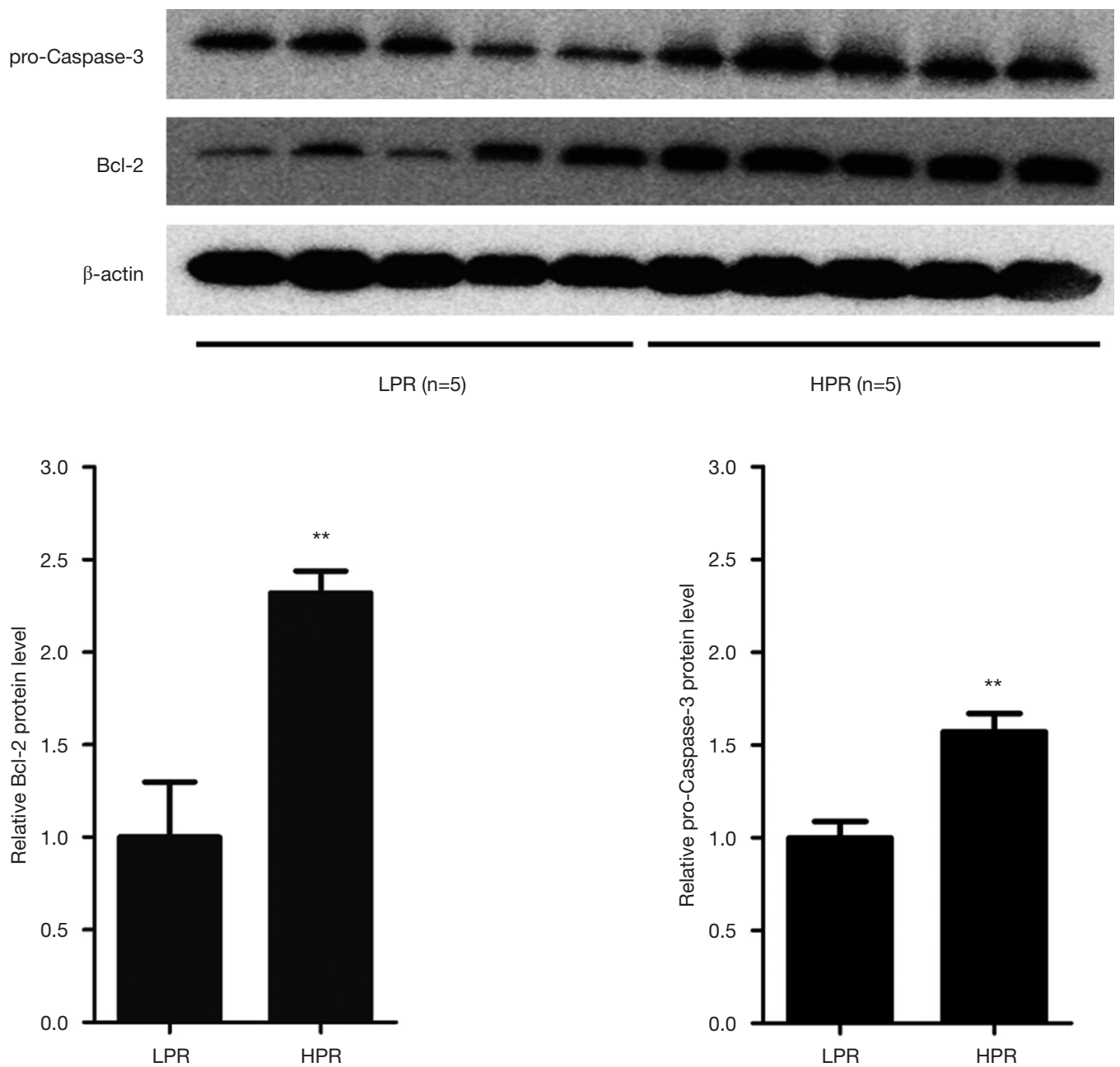

Figure 4 Upregulation of Bcl-2 and pro-Caspase-3 proteins in platelets of HPR patients. Western blot was performed to evaluate the levels of Bcl-2 and pro-Caspase-3 proteins in leukocyte-depleted platelets of five LPR and five HPR patients who underwent percutaneous coronary intervention. The relative expression of proteins was normalized to b-actin expression. The protein lysates were separated by $12 \%$ sodium dodecyl sulfate-polyacrylamide gel electrophoresis and then the filter was immunoblotted for Bcl-2, pro-Caspase-3 and b-actin. Error bars represent the SEM. **, $\mathrm{P}<0.01$. LPR, low platelet reaction; HPR, high platelet reactivity.

$\mathrm{P}=0.003$, Figure 4). These increases were consistent with decreased expression of platelet miR-15b in HPR patients.

\section{Platelet apoptosis is negatively correlated with platelet reactivity}

As the expression of platelet miR-15b was upregulated in LPR patients compared with HPR patients and the pivotal role of miR-15b in inducing cell apoptosis in MEG-01 cells was confirmed, we carried out further examination of the relationship between platelet apoptosis and platelet reactivity. We consecutively recruited another cohort of 44 patients who underwent PCI with drug-eluting stents; the baseline characteristics of these patients are displayed in Table 4. Platelet reactivity was shown in this cohort to be significantly correlated with a decreased rate of platelet apoptosis $(\mathrm{r}=-0.643, \mathrm{P}<0.001$, Figure $5 A)$. Linear regression analysis revealed that the proportion of platelet apoptosis was independently associated with platelet reactivity (standardized coefficients $\beta=-0.643$, $\mathrm{P}<0.001$, Table 5). Additionally, as the cut-off value of 235-240 PRU is commonly used to predict major adverse cardiovascular events, $(4,6,7,47)$, we divided the patients into two groups according to their platelet reactivity and 
Table 4 Characteristics of patients in the cohort of 44 patients

\begin{tabular}{|c|c|c|c|}
\hline Variables & $\begin{array}{c}\mathrm{PRU}<240 \\
\quad(\mathrm{n}=24)\end{array}$ & $\begin{array}{c}\mathrm{PRU} \geq 240 \\
(\mathrm{n}=20)\end{array}$ & $P$ \\
\hline \multicolumn{4}{|l|}{ Clinical parameters } \\
\hline Age (years) & $61.15 \pm 7.42$ & $62.44 \pm 7.43$ & 0.539 \\
\hline Male sex (\%) & 92.3 & 80.0 & 0.248 \\
\hline BMI (kg/m2) & $25.89 \pm 2.16$ & $24.97 \pm 2.61$ & 0.175 \\
\hline Hypertension (\%) & 69.2 & 76.0 & 0.588 \\
\hline Hyperlipidemia (\%) & 80.8 & 80.0 & 1.000 \\
\hline Diabetes (\%) & 30.8 & 32.0 & 0.925 \\
\hline $\begin{array}{l}\text { Family CAD } \\
\text { history (\%) }\end{array}$ & 19.2 & 20.0 & 1.000 \\
\hline Current Smoking (\%) & 30.8 & 28.0 & 0.828 \\
\hline LVEF & $58.42 \pm 8.16$ & $60.00 \pm 6.45$ & 0.449 \\
\hline \multicolumn{4}{|l|}{ Medications } \\
\hline PPI (\%) & 15.4 & 24.0 & 0.499 \\
\hline Nitrates (\%) & 100.0 & 100.0 & 1.000 \\
\hline$\beta$-blockers (\%) & 96.2 & 88.0 & 0.350 \\
\hline ACEI (\%) & 26.9 & 24.0 & 0.811 \\
\hline ARB (\%) & 19.2 & 24.0 & 0.679 \\
\hline CCB (\%) & 46.2 & 48.0 & 0.895 \\
\hline Statins (\%) & 100.0 & 100.0 & 1.000 \\
\hline \multicolumn{4}{|l|}{ Laboratory parameters } \\
\hline WBC counts $\left(10^{9} / L\right)$ & $6.27 \pm 1.71$ & $6.46 \pm 1.48$ & 0.670 \\
\hline Hemoglobin (g/L) & $147.77 \pm 12.88$ & $143.56 \pm 14.60$ & 0.280 \\
\hline Creatinine ( $\mu \mathrm{mol} / \mathrm{L})$ & $75.39 \pm 14.02$ & $77.44 \pm 12.84$ & 0.588 \\
\hline \multicolumn{4}{|l|}{$\mathrm{PCl}$ parameters } \\
\hline $\begin{array}{l}\text { No. of stents } \\
\text { implanted }\end{array}$ & $1.65 \pm 0.75$ & $1.76 \pm 0.78$ & 0.621 \\
\hline Drug-eluting stent (\%) & 100.0 & 100.0 & 1.000 \\
\hline $\begin{array}{l}\text { Left anterior } \\
\text { descending artery (\%) }\end{array}$ & 50.0 & 56.0 & 0.668 \\
\hline \multicolumn{4}{|c|}{ Platelet function parameters } \\
\hline $\begin{array}{l}\text { VerifyNow P2Y12 } \\
\text { (PRU) }\end{array}$ & $200.50 \pm 42.49$ & $271.68 \pm 20.68$ & $<0.001$ \\
\hline
\end{tabular}

Continuous variables are presented as mean \pm SD and categorical variables as percentage of the subjects. BMI, body mass index; CAD, coronary artery disease; LVEF, left ventricular ejection fraction; PPI, proton pump inhibitor; ACEI, angiotensinconverting enzyme inhibitor; $A R B$, angiotensin receptor blocker; CCB, calcium channel blocker; WBC, white blood cell; PRU, platelet reactivity unit; LPR, low platelet reactivity; HPR, high platelet reactivity.
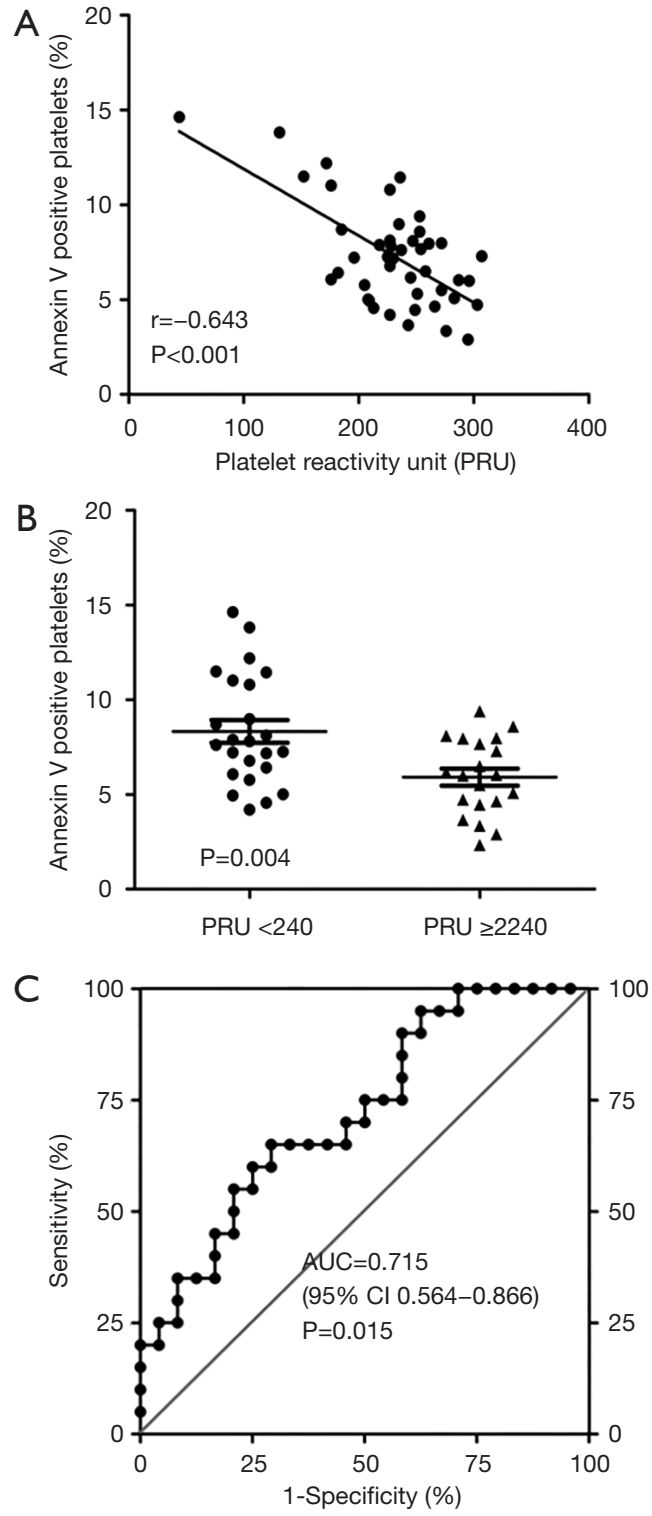

Figure 5 The correlation between platelet apoptosis and platelet reactivity. (A) Forty-four patients who underwent percutaneous coronary intervention were enrolled to assess platelet reactivity and platelet apoptosis. Platelet reactivity was measured by VerifyNow P2Y12 assay and platelet apoptosis was defined as Annexin V stained PS exposure in platelets (CD61 positive) using flow cytometry. Correlation between platelet reactivity and platelet apoptosis was determined using Pearson's correlation coefficient. (B) In this cohort, comparison of the rate of platelet apoptosis was performed between patients with PRU $<240$ ( $n=24)$ and PRU $\geq 240$ $(n=20)$. (C) ROC analysis was used to evaluate the ability of platelet apoptosis to distinguish between patients with PRU $\geq 240$ and PRU <240. PRU, platelet reactivity unit; AUC, area under curve; $\mathrm{CI}$, confidence interval; PS, phosphatidylserine; ROC, receiver operator characteristic. $\boldsymbol{\Delta}$ and $\boldsymbol{\Delta}$ represent a single patient. 
Table 5 Association between platelet apoptosis and platelet reactivity

\begin{tabular}{lccc}
\hline \multirow{2}{*}{ Variables } & \multicolumn{2}{c}{ Liner regression } & \multicolumn{2}{c}{ Binary logistic regression } \\
\cline { 2 - 4 } & Standardized coefficients $\beta$ & $\mathrm{P}$ & OR $(95 \% \mathrm{Cl})$ \\
\hline Platelet apoptosis & -0.643 & $<0.001$ & $1.52(1.10-2.10)$ \\
Age & - & 0.385 & - \\
\hline
\end{tabular}

$\mathrm{Cl}$, confidence interval; OR, odds ratio.

found that patients with PRU $\geq 240$ demonstrated lower levels of platelet apoptosis than those with PRU $<240$ $(\mathrm{P}=0.004$, Figure $5 B)$. Binary logistic regression analysis also revealed that apoptotic events in platelets were independently associated with lower levels of platelet reactivity [OR, 1.52 (95\% confidence interval, 1.10 to 2.10), $\mathrm{P}=0.012$, Table 4]. Furthermore, ROC curve analysis, allowed us to demonstrate a distinction between the rate of platelet apoptosis in patients with PRU $\geq 240$ and those with PRU $<240$. The area under the curve was 0.715 (95\% confidence interval, 0.564 to $0.866, \mathrm{P}=0.015$ ), and the optimal cut-off value was evaluated to be $6.64 \%$ (sensitivity $70.8 \%$, specificity $65.0 \%$ ) for platelet apoptosis to predict PRU <240 (Figure 5C). These results indicate an inverse relationship between platelet apoptosis and platelet reactivity in PCI patients.

\section{Induced platelet apoptosis attenuates platelet reactivity}

ABT-737, a Bcl-2 Homology 3 (BH3) mimetic, induces platelet apoptosis by inhibiting antiapoptotic Bcl-2 proteins (48-50). After incubation with platelet-rich plasma from PCI patients, ABT-737 promoted platelet apoptosis at a concentration of $2.5,5$ and $10 \mu \mathrm{M}$, reaching $11.4 \%$, $19.9 \%$ and $46.8 \%$ apoptotic events in platelets, respectively $(\mathrm{P}<0.001$, Figure $6 A, B)$. For verification of whether the higher rate of platelet apoptosis lead to reduced platelet reactivity, we assessed $\mathrm{ADP}$-induced platelet aggregation of apoptotic platelets. We observed that ABT-737 treatment decreased platelet aggregation in a dose-dependent manner, resulting in $42.4 \%, 38.5 \%$ and $29.6 \%$ of maximal platelet aggregation $(\mathrm{P}<0.001$, Figure $6 C)$. These results demonstrate that by inducing platelet apoptosis through inhibiting Bcl2, platelet reactivity of PCI patients is lowered in vitro.

\section{Discussion}

This study identified platelet miRNA expression profiles of patients who underwent PCI with drug-eluting stents.
A total of 420 different miRNAs were discovered in the platelets of PCI patients by our miRNA microarray analysis based on sanger miRBase (v 19.0) in total online: http:// fp.amegroups.cn/cms/c061c8aeaa78fef88a53bace5e60e62 a/atm.2020.02.88-1.pdf. We compared the mean levels of platelet miRNAs in our PCI patients with 284 miRNAs detected in healthy subjects in a previous study by Nagalla et al. (27). In total, 218 of our miRNAs coincided with theirs, and a significant relationship between the databases of the two studies was observed $\left(\mathrm{r}=0.780, \mathrm{P}=6.726 \times 10^{-46}\right.$, Figure S1).

Interestingly, among the HPR patients, we observed a trend of higher expression of platelet miR-15b ( $\mathrm{P}=0.068)$ and miR-145 $(\mathrm{P}=0.003)$ in females than in males, suggesting the existence of gender-related miRNAs in platelets. However, the platelet miRNA expression of males and females was not compared in LPR patients because only one female were recruited into the LPR group. Recently, Simon $e t$ al. reported gender- and age-associated networks of platelet miRNA and mRNA, and found that 54 mRNAs and 9 miRNAs were differentially expressed in platelets according to gender (51), which supports our study. How these gender-related miRNAs may regulate platelet function warrants further study.

Here, we report a negative relationship between platelet miR-15b expression and HPR, and the pivotal role platelet apoptosis has in platelet reactivity. Apoptosis or programmed cell death (PCD) serves as a control mechanism to remove damaged or unnecessary cells, and its involvement in the regulation of anucleated platelets has also been recognized (33-35). Platelet apoptosis is distinct from platelet activation $(34,35)$, and excessive apoptosis in platelets was proposed to be associated with some types of diseases such as myelodysplastic syndromes (MDS) (52), immune thrombocytopenia (ITP) (53), amyotrophic lateral sclerosis (ALS) (54), chronic uremia (55), malaria (56), and type 2 diabetes (57), which indicates that platelet apoptosis serves a role in manipulating hemostasis and thrombosis. During the pathogenesis of CHD, platelets adhere to 


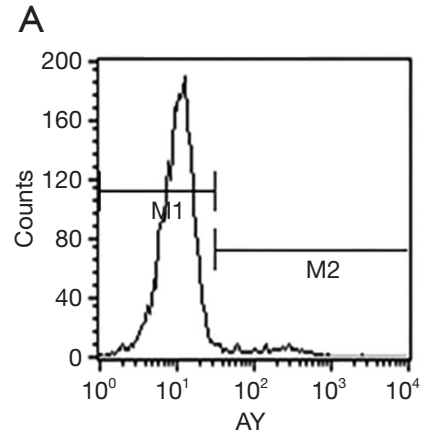

ABT-737 $(0 \mu \mathrm{M})$

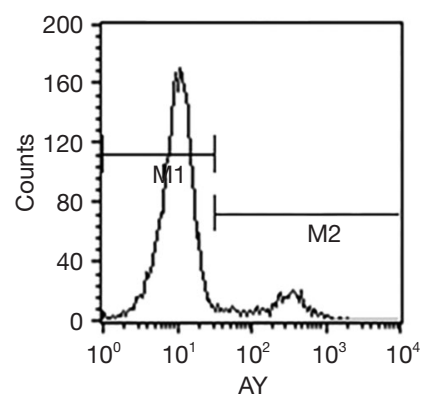

ABT-737 $(2.5 \mu \mathrm{M})$

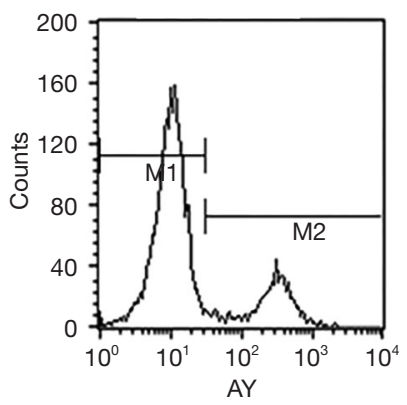

ABT-737 $(5 \mu \mathrm{M})$

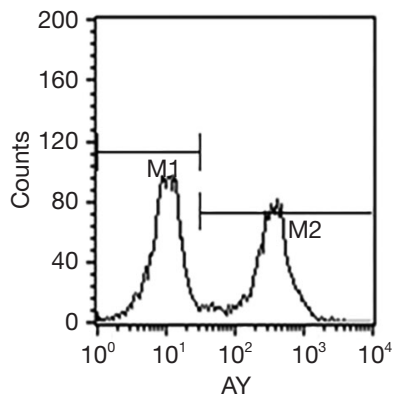

ABT-737 $(10 \mu \mathrm{M})$
B

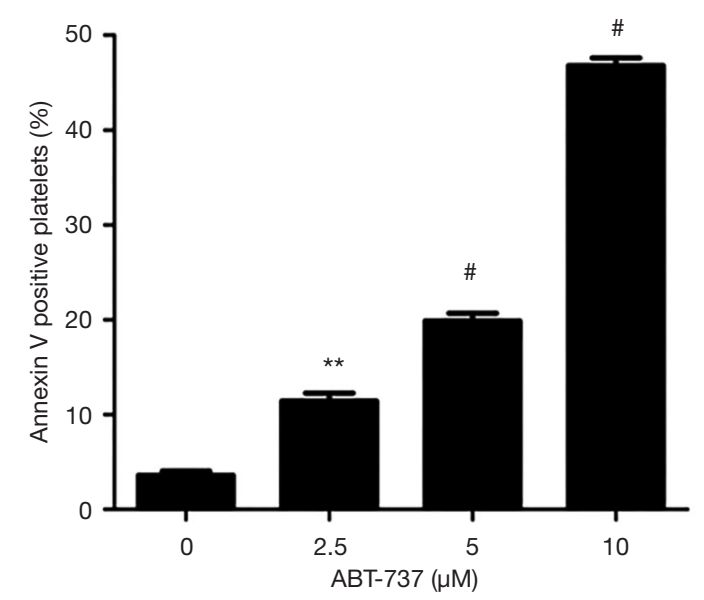

C

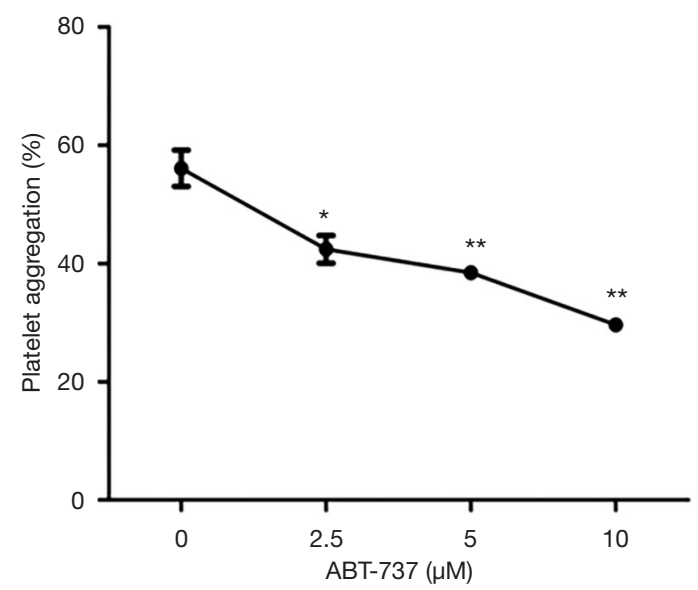

Figure 6 Induced platelet apoptosis attenuates platelet reactivity. (A) Platelet-rich plasma of patients undergoing percutaneous coronary intervention was incubated with ABT-737 $(0,2.5,5$ and $10 \mu \mathrm{M})$ for 2 hours at $37^{\circ} \mathrm{C}$, then platelet apoptosis was measured by flow cytometry. DMSO was used as a vehicle control of ABT-737. Platelet apoptosis was defined as Annexin V stained PS exposure in platelets (CD61 positive). (B) Data are presented as mean \pm SEM ( $n=3)$. (C) After ABT-737 treatment, platelet reactivity was evaluated by light transmittance aggregometry assay induced with $20 \mu \mathrm{M}$ adenosine diphosphate and $22 \mathrm{~nm}$ Prostaglandin E1. Data are mean $\pm \mathrm{SEM}\left(\mathrm{n}=3\right.$ ). ${ }^{*}, \mathrm{P}<0.05$; **, $\mathrm{P}<0.01 ;{ }^{*}, \mathrm{P}<0.001$. PS, phosphatidylserine.

damaged vessel walls where the endothelial cells are activated and platelet activation promotes the propagation of intracoronary thrombi after spontaneous disruption of atherosclerotic plaque $(58,59)$. The PCI procedure also activates platelets (60), and patients with higher levels of post-PCI (and post-antiplatelet therapy) platelet reactivity to ADP have adverse clinical outcomes (6-9). Nevertheless, the association between platelet apoptosis and platelet reactivity has not yet been investigated. Interestingly, the activation of platelet $\mathrm{P} 2 \mathrm{Y} 12$ receptors was demonstrated to attenuate platelet apoptosis induced by ABT-737 in vitro (61), suggesting a possible relationship between platelet aggregation and apoptosis. With that being said, platelet aggregation does not equate to platelet reactivity variation in response to antiplatelet drugs, and the mechanisms modulating the latter might be more complicated and delicate.

The relationship observed between platelet miR-15b and platelet reactivity and the role of miR-15b in apoptosis lead us to speculate that the diverse levels of platelet apoptosis may have had an impact on the interindividual variability of platelet reactivity. Indeed, we demonstrated a negative correlation between platelet apoptosis and platelet reactivity and platelet apoptosis as an independent predictor of 
platelet reactivity in PCI patients. HPR patients appeared to present lower levels of miR-15b in platelets, leading to relatively higher levels of $\mathrm{Bcl}-2$ protein and reduced platelet apoptosis, and relatively more "functional platelets" to induce platelet aggregation. On the other hand, LPR patients expressed higher levels of platelet miR-15b to enhance platelet apoptosis, which might attenuate the risk of HPR. To test whether induction of apoptosis in the platelets of HPR patients in vitro would decrease the levels of platelet reactivity, we treated platelet-rich plasma with ABT-737 at different concentrations, and found that ABT737 inhibited platelet aggregation in a dose-dependent manner, verifying the role of platelet apoptosis in protecting patients from HPR in vitro.

Our study has some limitations. We performed miRNA microarray analysis on a relatively small sample set of patients with LPR or HPR, with $\mathrm{n}=4$ in each group. However, we validated miR-15b in a larger sample of 39 patients by RT-qPCR. Additionally, in the RT-qPCR validation group, patients with HPR were found to be older and have lower levels of hemoglobin concentration than LPR. A stepwise binary logistic regression model observed that, besides decreased platelet miR-15b expression, age and gender were also independently associated with HPR, with older people and females more likely to have HPR, which coincided with previous studies (17-20). Hemoglobin concentration was excluded from this model due to its negative correlation with age $(\mathrm{r}=-0.359, \mathrm{P}=0.025)$. We further examined the relationship between age and platelet miR-15b expression. In a non-stratified population, we did not detect a statistically significant correlation between age and levels of platelet miR-15b $(\mathrm{P}=0.373)$. In patients with HPR, however, age was significantly and positively correlated with platelet miR-15b expression $(\mathrm{P}=0.007$, Figure S2), indicating that levels of platelet miR-15b might rise as age increases. Despite being older, HPR patients presented lower expression of platelet miR-15b than those with LPR. After adjustments to factor in age, the difference in platelet miR-15b expression between patients with LPR and HPR become even more significant $(\mathrm{P}=0.008)$.

In summary, we profiled the platelet miRNA expression patterns of patients who underwent PCI and demonstrated a novel link between miR-15b, platelet apoptosis, and platelet reactivity, suggesting a new approach to overcome HPR in PCI patients through promoting platelet apoptosis. In fact, besides ADP and arachidonic acid, other agonists such as thrombin, collagen and epinephrine are also able to induce platelet aggregation through other pathways (59).
This may be one of the reasons why thrombotic events still occur despite the clinical practice of dual antiplatelet therapy. However, enhanced platelet apoptosis provides a remarkable way to reduce residual "functional platelets", and in this way, platelet aggregation induced by a variety of agonists might be effectively and extensively inhibited. Considering that tailored antiplatelet therapy based on platelet function has had limited improvement on outcomes of PCI patients to date, in future, drugs which exclusively target antiapoptotic proteins in platelets may be introduced to overcome HPR in PCI patients. In addition, since platelet miR-15b expression and the proportion of platelet apoptosis are both significantly and inversely associated with HPR in PCI patients, both platelet miR-15b and platelet apoptosis bear hopes of serving as biomarkers for platelet reactivity or even high risk ischemic/bleeding events.

\section{Acknowledgments}

The authors thank: Dr. Jue Ye and Dr. Zihe Yang for the guidance of RT-qPCR and cell transfection experiment; Dr Yingjie Wei and Dr Jun Li for the assistance with PCR experiment; and Dr Li Ma for the help with platelet aggregation experiment.

Funding: This work was supported by the National Natural Science Foundation of China (81170194).

\section{Footnote}

Conflicts of Interest: The authors have no conflicts of interest to declare.

Ethical Statement: The authors are accountable for all aspects of the work in ensuring that questions related to the accuracy or integrity of any part of the work are appropriately investigated and resolved. The study protocol was approved by the Medical Ethics Committee of Fuwai Hospital of Peking Union Medical College and the Chinese Academy of Medical Sciences. Written informed consent was obtained from each patient.

Open Access Statement: This is an Open Access article distributed in accordance with the Creative Commons Attribution-NonCommercial-NoDerivs 4.0 International License (CC BY-NC-ND 4.0), which permits the noncommercial replication and distribution of the article with the strict proviso that no changes or edits are made and the original work is properly cited (including links to both the 
formal publication through the relevant DOI and the license). See: https://creativecommons.org/licenses/by-nc-nd/4.0/.

\section{References}

1. Levine GN, Bates ER, Blankenship JC, et al. 2011 ACCF/AHA/SCAI Guideline for Percutaneous Coronary Intervention. A report of the American College of Cardiology Foundation/American Heart Association Task Force on Practice Guidelines and the Society for Cardiovascular Angiography and Interventions. J Am Coll Cardiol 2011;58:e44-122.

2. Jneid H, Anderson JL, Wright RS, et al. 2012 ACCF/AHA focused update of the guideline for the management of patients with unstable angina/non-ST-elevation myocardial infarction (updating the 2007 guideline and replacing the 2011 focused update): a report of the American College of Cardiology Foundation/American Heart Association Task Force on Practice Guidelines. J Am Coll Cardiol 2012;60:645-81.

3. O'Gara PT, Kushner FG, Ascheim DD, et al. 2013 ACCF/ AHA guideline for the management of ST-elevation myocardial infarction: a report of the American College of Cardiology Foundation/American Heart Association Task Force on Practice Guidelines. J Am Coll Cardiol 2013;61:e78-140.

4. Marcucci R, Gori AM, Paniccia R, et al. Cardiovascular death and nonfatal myocardial infarction in acute coronary syndrome patients receiving coronary stenting are predicted by residual platelet reactivity to ADP detected by a point-of-care assay: a 12 -month follow-up. Circulation 2009;119:237-42.

5. Sibbing D, Schulz S, Braun S, et al. Antiplatelet effects of clopidogrel and bleeding in patients undergoing coronary stent placement. J Thromb Haemost 2010;8:250-6.

6. Breet NJ, van Werkum JW, Bouman HJ, et al. Comparison of platelet function tests in predicting clinical outcome in patients undergoing coronary stent implantation. JAMA 2010;303:754-62.

7. Campo G, Parrinello G, Ferraresi P, et al. Prospective evaluation of on-clopidogrel platelet reactivity over time in patients treated with percutaneous coronary intervention relationship with gene polymorphisms and clinical outcome. J Am Coll Cardiol 2011;57:2474-83.

8. Brar SS, ten Berg J, Marcucci R, et al. Impact of platelet reactivity on clinical outcomes after percutaneous coronary intervention. A collaborative meta-analysis of individual participant data. J Am Coll Cardiol 2011;58:1945-54.
9. Mangiacapra F, Patti G, Barbato E, et al. A therapeutic window for platelet reactivity for patients undergoing elective percutaneous coronary intervention: results of the ARMYDA-PROVE (Antiplatelet therapy for Reduction of MYocardial Damage during Angioplasty-Platelet Reactivity for Outcome Validation Effort) study. JACC Cardiovasc Interv 2012;5:281-9.

10. Stone GW, Witzenbichler B, Weisz G, et al. Platelet reactivity and clinical outcomes after coronary artery implantation of drug-eluting stents (ADAPT-DES): a prospective multicentre registry study. Lancet 2013;382:614-23.

11. Laine M, Toesca R, Berbis J, et al. Platelet reactivity evaluated with the VASP assay following ticagrelor loading dose in acute coronary syndrome patients undergoing percutaneous coronary intervention. Thromb Res 2013;132:e15-8.

12. Perl L, Lerman-Shivek H, Rechavia E, et al. Response to prasugrel and levels of circulating reticulated platelets in patients with ST-segment elevation myocardial infarction. J Am Coll Cardiol 2014;63:513-7.

13. Wiviott SD, Braunwald E, McCabe CH, et al. Prasugrel versus clopidogrel in patients with acute coronary syndromes. N Engl J Med 2007;357:2001-15.

14. Wallentin L, Becker RC, Budaj A, et al. Ticagrelor versus clopidogrel in patients with acute coronary syndromes. $\mathrm{N}$ Engl J Med 2009;361:1045-57.

15. DiNicolantonio JJ, D'Ascenzo F, Tomek A, et al. Clopidogrel is safer than ticagrelor in regard to bleeds: a closer look at the PLATO trial. Int J Cardiol 2013;168:1739-44.

16. Ang L, Palakodeti V, Khalid A, et al. Elevated plasma fibrinogen and diabetes mellitus are associated with lower inhibition of platelet reactivity with clopidogrel. J Am Coll Cardiol 2008;52:1052-9.

17. Price MJ, Nayak KR, Barker CM, et al. Predictors of heightened platelet reactivity despite dual-antiplatelet therapy in patients undergoing percutaneous coronary intervention. Am J Cardiol 2009;103:1339-43.

18. Elsenberg EH, van Werkum JW, van de Wal RM, et al. The influence of clinical characteristics, laboratory and inflammatory markers on 'high on-treatment platelet reactivity' as measured with different platelet function tests. Thromb Haemost 2009;102:719-27.

19. Silvain J, Cayla G, Hulot JS, et al. High on-thienopyridine platelet reactivity in elderly coronary patients: the SENIOR-PLATELET study. Eur Heart J 2012;33:1241-9. 20. Hochholzer W, Trenk D, Fromm MF, et al. Impact of 
cytochrome P450 2C19 loss-of-function polymorphism and of major demographic characteristics on residual platelet function after loading and maintenance treatment with clopidogrel in patients undergoing elective coronary stent placement. J Am Coll Cardiol 2010;55:2427-34.

21. Shuldiner AR, O'Connell JR, Bliden KP, et al. Association of cytochrome P450 2C19 genotype with the antiplatelet effect and clinical efficacy of clopidogrel therapy. JAMA 2009;302:849-57.

22. Mega JL, Close SL, Wiviott SD, et al. Cytochrome p-450 polymorphisms and response to clopidogrel. $\mathrm{N}$ Engl J Med 2009;360:354-62.

23. Sibbing D, Stegherr J, Latz W, et al. Cytochrome P450 2C19 loss-of-function polymorphism and stent thrombosis following percutaneous coronary intervention. Eur Heart J 2009;30:916-22.

24. Nakahara K, Carthew RW. Expanding roles for miRNAs and siRNAs in cell regulation. Curr Opin Cell Biol 2004;16:127-33.

25. Bartel DP. MicroRNAs: target recognition and regulatory functions. Cell 2009;136:215-33.

26. Landry P, Plante I, Ouellet DL, et al. Existence of a microRNA pathway in anucleate platelets. Nat Struct Mol Biol 2009; 16:961-6.

27. Nagalla S, Shaw C, Kong X, et al. Platelet microRNAmRNA coexpression profiles correlate with platelet reactivity. Blood 2011;117:5189-97.

28. Xu X, Gnatenko DV, Ju J, et al. Systematic analysis of microRNA fingerprints in thrombocythemic platelets using integrated platforms. Blood 2012;120:3575-85.

29. Willeit P, Zampetaki A, Dudek K, et al. Circulating microRNAs as novel biomarkers for platelet activation. Circ Res 2013;112:595-600.

30. Shi R, Ge L, Zhou X, et al. Decreased platelet miR-223 expression is associated with high on-clopidogrel platelet reactivity. Thromb Res 2013;131:508-13.

31. Zhang YY, Zhou X, Ji WJ, et al. Decreased circulating microRNA-223 level predicts high on-treatment platelet reactivity in patients with troponin-negative non-ST elevation acute coronary syndrome. J Thromb Thrombolysis 2014;38:65-72.

32. Kondkar AA, Bray MS, Leal SM, et al. VAMP8/ endobrevin is overexpressed in hyperreactive human platelets: suggested role for platelet microRNA. J Thromb Haemost 2010;8:369-78.

33. Leytin V. Apoptosis in the anucleate platelet. Blood Rev 2012;26:51-63.

34. Schoenwaelder SM, Yuan Y, Josefsson EC, et al. Two distinct pathways regulate platelet phosphatidylserine exposure and procoagulant function. Blood 2009;114:663-6.

35. Leytin V, Allen DJ, Mutlu A, et al. Platelet activation and apoptosis are different phenomena: evidence from the sequential dynamics and the magnitude of responses during platelet storage. Br J Haematol 2008;142:494-7.

36. Krek A, Grun D, Poy MN, et al. Combinatorial microRNA target predictions. Nat Genet 2005;37:495-500.

37. Wang X, El Naqa IM. Prediction of both conserved and nonconserved microRNA targets in animals. Bioinformatics 2008;24:325-32.

38. Betel D, Wilson M, Gabow A, et al. The microRNA. org resource: targets and expression. Nucleic Acids Res 2008;36:D149-53.

39. Xia L, Zhang D, Du R, et al. miR-15b and miR-16 modulate multidrug resistance by targeting BCL2 in human gastric cancer cells. Int J Cancer 2008;123:372-9.

40. Guo CJ, Pan Q, Li DG, et al. miR-15b and miR-16 are implicated in activation of the rat hepatic stellate cell: An essential role for apoptosis. J Hepatol 2009;50:766-78.

41. An F, Gong B, Wang H, et al. miR-15b and miR-16 regulate TNF mediated hepatocyte apoptosis via BCL2 in acute liver failure. Apoptosis 2012;17:702-16.

42. Heger J, Abdallah Y, Shahzad T, et al. Transgenic overexpression of the adenine nucleotide translocase 1 protects cardiomyocytes against TGFbeta1-induced apoptosis by stabilization of the mitochondrial permeability transition pore. J Mol Cell Cardiol 2012;53:73-81.

43. Xiao J, Sun B, Li M, et al. A novel adipocytokine visfatin protects against $\mathrm{H}(2) \mathrm{O}(2)$-induced myocardial apoptosis: a missing link between obesity and cardiovascular disease. J Cell Physiol 2013;228:495-501.

44. Li XQ, Ouyang ZG, Zhang SH, et al. Synergy of enediyne antibiotic lidamycin and temozolomide in suppressing glioma growth with potentiated apoptosis induction. J Neurooncol 2014;119:91-100.

45. Kim EA, Jang JH, Lee YH, et al. Dioscin induces caspase-independent apoptosis through activation of apoptosis-inducing factor in breast cancer cells. Apoptosis 2014;19:1165-75.

46. Kang M, Jeong CW, Ku JH, et al. Inhibition of autophagy potentiates atorvastatin-induced apoptotic cell death in human bladder cancer cells in vitro. Int J Mol Sci 2014;15:8106-21.

47. Patti G, Nusca A, Mangiacapra F, et al. Point-of-care measurement of clopidogrel responsiveness predicts clinical outcome in patients undergoing percutaneous 
coronary intervention results of the ARMYDA-PRO (Antiplatelet therapy for Reduction of MYocardial Damage during Angioplasty-Platelet Reactivity Predicts Outcome) study. J Am Coll Cardiol 2008;52:1128-33.

48. Zhang H, Nimmer PM, Tahir SK, et al. Bcl-2 family proteins are essential for platelet survival. Cell Death Differ 2007;14:943-51.

49. Vogler M, Hamali HA, Sun XM, et al. BCL2/BCL-X(L) inhibition induces apoptosis, disrupts cellular calcium homeostasis, and prevents platelet activation. Blood 2011;117:7145-54.

50. Rukoyatkina N, Mindukshev I, Walter U, et al. Dual role of the $\mathrm{p} 38 \mathrm{MAPK} / \mathrm{cPLA} 2$ pathway in the regulation of platelet apoptosis induced by ABT-737 and strong platelet agonists. Cell Death Dis 2013;4:e931.

51. Simon LM, Edelstein LC, Nagalla S, et al. Human platelet microRNA-mRNA networks associated with age and gender revealed by integrated plateletomics. Blood 2014;123:e37-45.

52. Martín M, de Paz R, Jimenez-Yuste V, et al. Platelet apoptosis and agonist-mediated activation in myelodysplastic syndromes. Thromb Haemost 2013;109:909-19.

53. Wang JD, Ou TT, Wang CJ, et al. Platelet apoptosis resistance and increased CXCR4 expression in pediatric patients with chronic immune thrombocytopenic purpura.

Cite this article as: Wang J, Yao Y, Zhang J, Tang X, Meng X, Wang M, Song L, Yuan J. Platelet microRNA-15b protects against high platelet reactivity in patients undergoing percutaneous coronary intervention through Bcl-2-mediated platelet apoptosis. Ann Transl Med 2020;8(6):364. doi: 10.21037/atm.2020.02.88
Thromb Res 2010;126:311-8.

54. Shrivastava M, Vivekanandhan S, Pati U, et al. Mitochondrial perturbance and execution of apoptosis in platelet mitochondria of patients with amyotrophic lateral sclerosis. Int J Neurosci 2011;121:149-58.

55. Bonomini M, Dottori S, Amoroso L, et al. Increased platelet phosphatidylserine exposure and caspase activation in chronic uremia. J Thromb Haemost 2004;2:1275-81.

56. Piguet PF, Kan CD, Vesin C. Thrombocytopenia in an animal model of malaria is associated with an increased caspase-mediated death of thrombocytes. Apoptosis 2002;7:91-8.

57. Cohen Z, Gonzales RF, Davis-Gorman GF, et al. Thrombin activity and platelet microparticle formation are increased in type 2 diabetic platelets: a potential correlation with caspase activation. Thromb Res 2002;107:217-21.

58. Falk E, Shah PK, Fuster V. Coronary plaque disruption. Circulation 1995;92:657-71.

59. Davì G, Patrono C. Platelet activation and atherothrombosis. N Engl J Med 2007;357:2482-94.

60. Kereiakes DJ, Gurbel PA. Peri-procedural platelet function and platelet inhibition in percutaneous coronary intervention. JACC Cardiovasc Interv 2008;1:111-21.

61. Zhang S, Ye J, Zhang Y, et al. P2Y12 protects platelets from apoptosis via PI3k-dependent Bak/Bax inactivation. J Thromb Haemost 2013;11:149-60. 


\section{Supplementary}

Table S1 Characteristics of patients for miRNA microarray study

\begin{tabular}{|c|c|c|c|}
\hline Variables & $\begin{array}{l}\text { LPR group } \\
\qquad(n=4)\end{array}$ & $\begin{array}{l}\text { HPR group } \\
\qquad(n=4)\end{array}$ & $\mathrm{P}$ \\
\hline \multicolumn{4}{|l|}{ Clinical parameters } \\
\hline Age (years) & $61.25 \pm 8.26$ & $58.25 \pm 6.45$ & 0.588 \\
\hline Male sex (\%) & 75 & 75 & 1.000 \\
\hline BMI $\left(\mathrm{kg} / \mathrm{m}^{2}\right)$ & $24.78 \pm 2.66$ & $28.26 \pm 2.48$ & 0.104 \\
\hline Hypertension (\%) & 75.0 & 75.0 & 1.000 \\
\hline Hyperlipidemia (\%) & 50.0 & 100.0 & 0.429 \\
\hline Diabetes (\%) & 50.0 & 50.0 & 1.000 \\
\hline $\begin{array}{l}\text { Family CAD } \\
\text { history (\%) }\end{array}$ & 25.0 & 25.0 & 1.000 \\
\hline $\begin{array}{l}\text { Currently } \\
\text { smoking (\%) }\end{array}$ & 50.0 & 25.0 & 1.000 \\
\hline LVEF & $66.67 \pm 6.43$ & $64.50 \pm 3.32$ & 0.581 \\
\hline \multicolumn{4}{|l|}{ Medications } \\
\hline PPI (\%) & 0.0 & 25.0 & 1.000 \\
\hline Nitrates (\%) & 100.0 & 100.0 & 1.000 \\
\hline$\beta$-blockers (\%) & 100.0 & 100.0 & 1.000 \\
\hline ACEI (\%) & 25.0 & 0.0 & 1.000 \\
\hline ARB (\%) & 0.0 & 50.0 & 0.429 \\
\hline CCB (\%) & 100.0 & 75.0 & 1.000 \\
\hline Statins (\%) & 100.0 & 100.0 & 1.000 \\
\hline \multicolumn{4}{|l|}{ Laboratory parameters } \\
\hline WBC counts $\left(10^{9} / \mathrm{L}\right)$ & $7.06 \pm 1.28$ & $7.86 \pm 0.29$ & 0.300 \\
\hline Hemoglobin (g/L) & $140.25 \pm 16.19$ & $145.25 \pm 13.05$ & 0.576 \\
\hline Creatinine $(\mu \mathrm{mol} / \mathrm{L})$ & $76.35 \pm 17.14$ & $76.05 \pm 5.73$ & 0.975 \\
\hline \multicolumn{4}{|l|}{$\mathrm{PCl}$ parameters } \\
\hline $\begin{array}{l}\text { No. of stents } \\
\text { implanted }\end{array}$ & $1.50 \pm 0.58$ & $3.00 \pm 1.16$ & 0.059 \\
\hline $\begin{array}{l}\text { Drug-eluting } \\
\text { stent (\%) }\end{array}$ & 100.0 & 100.0 & 1.000 \\
\hline $\begin{array}{l}\text { Left anterior } \\
\text { descending artery }\end{array}$ & 50.0 & 25.0 & 1.000 \\
\hline \multicolumn{4}{|c|}{ Platelet function parameters } \\
\hline $\begin{array}{l}\text { VerifyNow P2Y12 } \\
\text { (PRU), 1st day }\end{array}$ & $159.00 \pm 11.17$ & $326.00 \pm 17.78$ & $<0.001$ \\
\hline $\begin{array}{l}\text { VerifyNow P2Y12 } \\
\text { (PRU), 2nd day }\end{array}$ & $160.00 \pm 9.83$ & $319.25 \pm 11.24$ & $<0.001$ \\
\hline
\end{tabular}

Continuous variables are presented as mean \pm SD and categorical variables as percentage of the subjects. BMI, body mass index; CAD, coronary artery disease; LVEF, left ventricular ejection fraction; PPI, proton pump inhibitor; $\mathrm{ACEI}$, angiotensinconverting enzyme inhibitor; $\mathrm{ARB}$, angiotensin receptor blocker; CCB, calcium channel blocker; WBC, white blood cell; PRU, platelet reactivity unit; LPR, low platelet reactivity; HPR, high platelet reactivity. 


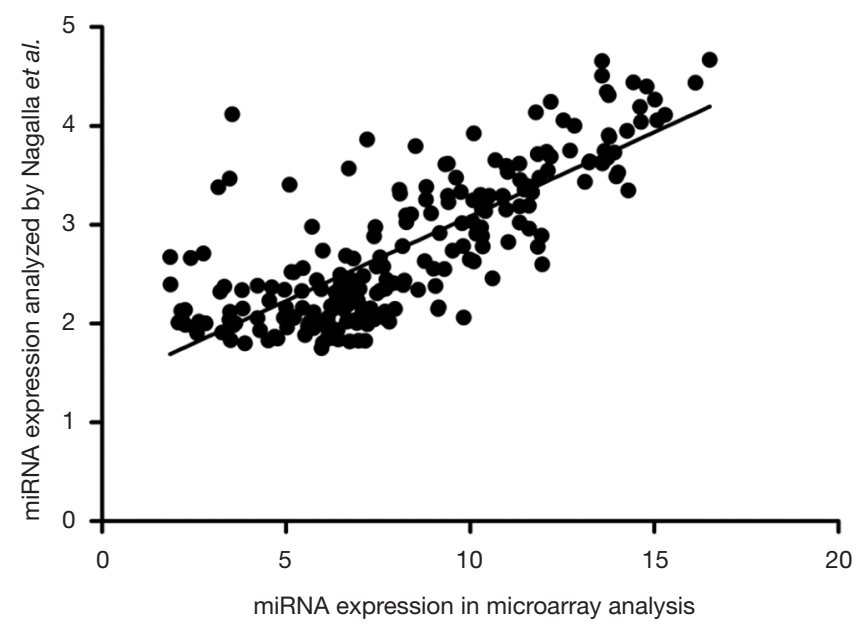

Figure S1 The correlation of miRNA expression in platelets between our microarray analysis and Nagalla et al. study. Correlation between the databases was determined using Pearson's correlation coefficient. - represents a single miRNA.

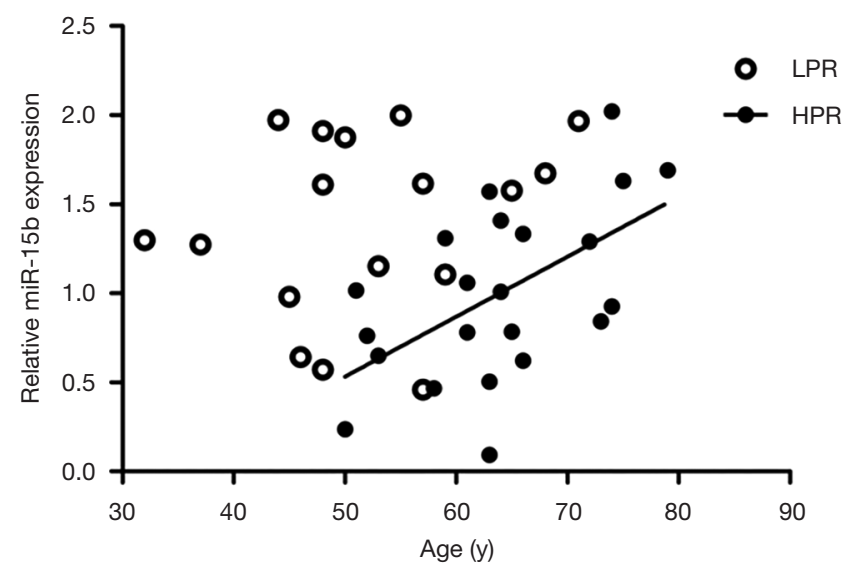

Figure S2 The correlation between levels of platelet miR-15b and ages of patients. By Pearson's correlation coefficient, there was no significant correlation between platelet miR-15b expression and ages of the patients $(\mathrm{P}=0.373)$. Whereas in HPR patients, ages were significantly and positively correlated with platelet miR-15b expression $(\mathrm{P}=0.007)$. LPR, low platelet reaction; HPR, high platelet reactivity. 